\title{
Relecturas de Malvinas y la política exterior argentina (1989- 2019)
}

URIEL ERLICH

Resumen: Nos proponemos analizar los últimos treinta años de la política exterior argentina sobre las Islas Malvinas, a partir del restablecimiento de las relaciones bilaterales entre Argentina y Reino Unido en 1989. Abordaremos las etapas de la política exterior, partiendo de las voces de los decisores de política de los distintos gobiernos, releyendo los cambios y las continuidades de la Cuestión Malvinas en sus distintos contextos históricos.

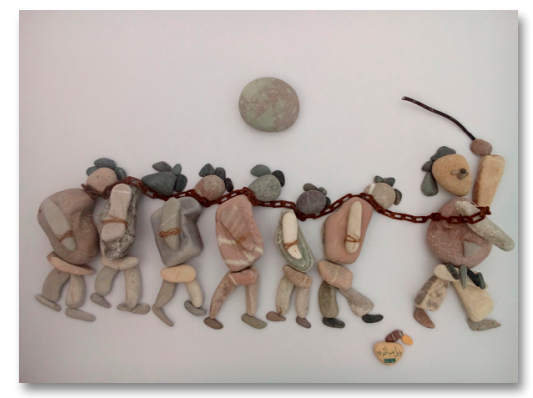

Palavras claves: Malvinas. Soberania. Argentina. Reino Unido. Colonialismo.

\section{Re-reading of Malvinas and Argentine foreign policy (1989-2019)}

\footnotetext{
URIEL ERLICH

Professor de Sociologia da Universidad de Buenos Aires / UBA. Pesquisador do Centro de Investigación para los trabajadores, Universidad Metropolitana para Educación y Trabajo (CITRA-UMET/ CONICET). Mestre em Políticas Públicas (Georgetown University) e doutorando em Ciências Sociais (UBA).

E-mail urielerlich@gmail.com
}

\begin{abstract}
We analyze the last thirty years of Argentine foreign policy over the Malvinas Islands, from the restart of bilateral relations between Argentina and the United Kingdom in 1989. We look at the stages of foreign policy, starting from the voices of decision-makers of different governments, rereading the changes and continuities of the Malvinas Question in their different historical contexts.
\end{abstract}

Keywords: Malvinas. Sovereignty. Argentina. United Kingdom. Colonialism.

RECEBIDO EM: 10/02/2019

Aprovado EM: 05/03/2019 


\section{INTRODUCCIÓN}

En palabras del reconocido historiador inglés, Eric Hobsbawn, el año 1989 marcó el "final del siglo XX corto" (HOBSBAWM, 2001). En cuanto a la Cuestión Malvinas, fue el año en el que se restablecieron las relaciones bilaterales entre Argentina y el Reino Unido, tras el conflicto bélico de 1982.

Nos proponemos abordar la política exterior argentina en la Cuestión de las Islas Malvinas en el período 1989-2019: los treinta años que han transcurrido a partir del restablecimiento de relaciones bilaterales entre Argentina y Reino Unido en 1989, tras el conflicto bélico de 1982. Para realizar este recorrido, partiremos de las perspectivas, diagnósticos y objetivos de los decisores de política de los distintos gobiernos, abordando el desarrollo de la Cuestión Malvinas en sus distintos contextos históricos, con sus cambios y continuidades.

La Cuestión de las Islas Malvinas, según Naciones Unidas, es uno de los últimos diecisiete casos de colonialismo (Territorios No Autónomos/ Non-self-governing territories) reconocidos en el mundo que se encuentran bajo tratamiento del "Comité de los $24^{\prime \prime}:{ }^{1}$ se trata de uno de los últimos casos que por mandato de dicho organismo deben ser objeto de descolonización. En cuanto al Reino Unido, diez de estos diecisiete casos aun vigentes (alrededor del 60\%) se encuentran bajo su dominio.

La Cuestión de las Islas Malvinas es el diferendo de soberanía entre Argentina y el Reino Unido por las Islas Malvinas, Sandwich del Sur, Georgias del Sur y los espacios marítimos circundantes, tal como lo entienden las Naciones Unidas desde el año 1965, a partir de la Resolución 2065 (XX), la cual reconoce dos partes de la disputa, Argentina y Reino Unido de Gran Bretaña e Irlanda del Norte, y las llama a negociar a fin de encontrar una solución pacífica a la disputa de soberanía.

Desde el inicio de la ocupación británica por la fuerza de las Islas Malvinas, en enero de 1833, este caso de colonialismo se

$1 \mathrm{Su}$ nombre completo es "Comité Especial encargado de examinar la situación con respecto a la aplicación de la Declaración sobre la concesión de la independencia a los países y pueblos coloniales". 
vincula con la región. A pocos meses de la ocupación, el gobierno de Bolivia envió un oficio al gobierno argentino sobre la ocupación de las Islas Malvinas, del que resulta interesante retomar un fragmento:

[...] Este suceso desagradable ha causado en el gobierno de Bolivia los sentimientos de desconsuelo que antes de ahora experimentó al ver que intereses mal entendidos frustraron el grandioso proyecto del Congreso de Panamá. La hermandad habría dado a las naciones de América toda la respetabilidad necesaria para que las naciones europeas se abstuvieran de emprender agresiones desconocidas por el derecho internacional, para repelerlas con vigor en el caso de que se avanzase con medias violentas. La ocupación de la Soledad, sin alegar título alguno y sin otro apoyo que el abuso de la prepotencia, ha sido, en extremo sensible al gobierno de Bolivia, que respetando sobremanera los derechos de toda nación, quisiera que de todas ellas se desterraran las vías de puro hecho, tan contrarias a la razón y las luces del siglo En violación tan manifiesta del derecho de gentes hay que considerar no sólo el ultraje hecho a la República Argentina sino también el desprecio que envuelve hacia las demás naciones americanas [...] la conducta del Gabinete Británico en las Malvinas, aunque sea perjudicial al gobierno que se siente despojado de su posesión, es ofensivo y demasiado injurioso a todas las repúblicas americanas, y, a juicio del gobierno de Bolivia, es un asunto altamente continental. (Oficio del Dr. Mariano Enrique Calvo, Min. De Relaciones Exteriores del Gobierno de Bolivia, enviado al Dr. Manuel García, Ministro de Relaciones Exteriores de Argentina, 14 de junio de 1833).

El oficio enviado presenta, al menos, dos elementos a destacar: por un lado, la crítica a la Argentina por no haber participado del Congreso de Panamá en 1826, que hubiera contribuido a que las naciones europeas se abstuvieran de emprender agresiones desconocidas por el derecho internacional. Por el otro, el apoyo de Bolivia al legítimo reclamo argentino, desde el mismo inicio del conflicto en 1833, asunto que es considerado altamente continental. 
Entendemos el colonialismo como la doctrina y la práctica institucional y política de la colonización. Siguiendo a Bobbio, Matteucci y Pasquino (1991, p. 238), se trata del "proceso de expansión y de conquista de colonias, la sumisión por medio del uso de la fuerza o de la superioridad económica de territorios habitados por poblaciones distintas de las de la potencia colonial". Se trata de la organización de sistemas de dominio.

La particularidad del caso de las Islas Malvinas es que la colonización no se produjo "sobre una población distinta de la potencia colonial". La política británica del siglo XIX se centró en poblar las Islas Malvinas mediante ciudadanos de los pueblos periféricos de Gran Bretaña, aplicando desde entonces un estricto control poblacional y de posesión de tierras. La ocupación de las islas en 1833 se enmarcó en "la política imperialista de las potencias europeas durante el siglo XIX en América, Asia y África" (ERLICH, 2015, p. 36).

Desde la ocupación de las Islas, en enero de 1834, a un año del desembarco británico y tras siete meses sin responder la protesta del ministro argentino, Manuel Moreno, el secretario de negocios extranjeros de Gran Bretaña, lord Palmerston, respondió que esperaba que el gobierno de las Provincias Unidas se diera por satisfecho y dejara de discutir los derechos soberanos de Su Majestad sobre las islas. "En adelante, la contraseña en el Foreign Office fue no responder a las reclamaciones argentinas sino con una negativa canés de reiniciar la discusión" (GROUSSAC, 1982, s/p.), lo cual se mantuvo hasta el año 1965.

El 16 de diciembre de 1965 la Asamblea General de las Naciones Unidas aprobó la Resolución 2065 (XX), y dio inicio a un período de negociaciones bilaterales. Dicha resolución:

1. Invita a los Gobiernos de la Argentina y del Reino Unido de Gran Bretaña e Irlanda del Norte a proseguir sin demora las negociaciones recomendadas por el Comité Especial encargado de examinar la situación con respecto a la aplicación de la Declaración sobre la concesión de la independencia a los países y pueblos coloniales a fin de encontrar una solución pacífica al problema, teniendo debidamente en cuenta las disposiciones y los objetivos de la Carta de las Naciones Unidas y de la resolución 1514 (XV) de la Asamblea 
General, así como los intereses de la población de las Islas Malvinas (Falkland Islands);

2. Pide a ambos Gobiernos que informen al Comité Especial y a la Asamblea General, en el vigésimo primer período de sesiones, sobre el resultado de las negociaciones. (NU, 1965, s/p.).

Entre 1965 y 1982, en el contexto del proceso de descolonización y a partir de la Resolución 2065 (XX) se inició un proceso de negociaciones entre Argentina y el Reino Unido sobre la soberanía de las Islas Malvinas y sobre diversos asuntos prácticos. Las negociaciones sobre asuntos prácticos dieron como resultado los Acuerdos de Comunicaciones de 1971-1972; las negociaciones sobre la soberanía incluyeron borradores de propuestas de solución del diferendo que no lograron concretarse (en 1974, 1980, 1981), y se mantuvieron, con intermitencias, hasta el conflicto bélico del año 1982. ${ }^{2}$

Tras el conflicto bélico, el Reino Unido decidió no volver a sentarse a dialogar sobre la soberanía de las Islas Malvinas, desconociendo más de doscientas resoluciones de organismos regionales e internacionales que llaman a las partes a retomar las negociaciones para encontrar, por la vía pacífica, una solución definitiva a la disputa de soberanía.

Entre 1983 y 1989 no hubo relaciones bilaterales formales entre Argentina y el Reino Unido, fue un periodo de distancia. Argentina proponía restablecer las relaciones bilaterales, incluyendo la soberanía de las Islas Malvinas como parte de la agenda. La renuencia británica a ello, imposibilitó su concreción.

Para la Argentina, el logro fundamental de este periodo fueron las Resoluciones anuales de la Asamblea General de Naciones Unidas, que convocaban a las partes, año tras año, a retomar las negociaciones por la soberanía: el diferendo continuaba vigente, y pendiente de resolución. En esta etapa se sentaron también las bases de lo que luego fueron los Acuerdos de Madrid y el restablecimiento de relaciones bilaterales, bajo el siguiente gobierno argentino.

2 Para un mayor desarrollo del período, ver Erlich (2015). 


\section{EL PÉNDULO: 1989-2019}

La política exterior argentina sobre las Islas Malvinas presenta un movimiento pendular entre dos principales posiciones (ERLICH, 2015): ${ }^{3}$ una de ellas plantea que la discusión sobre la soberanía de las Islas Malvinas debe ser parte central de la agenda con el Reino Unido desde el inicio de las negociaciones que puedan entablarse entre ambos países. La otra, propone una política que si bien no es opuesta, parte de un diagnóstico diferente: en tanto no es posible obligar al Reino Unido a discutir la soberanía, se debe cooperar sobre otros asuntos prácticos (recursos pesqueros, hidrocarburos, comunicaciones, etc.) como modo de iniciar un camino de entendimientos que se espera que contribuya, en un mediano plazo, a abordar la discusión de fondo por la soberanía.

Dicho movimiento de la política en la Cuestión Malvinas, a su vez, es acompasado por el movimiento pendular de la política exterior: ${ }^{4}$ aquellos gobiernos argentinos que han centrado su política exterior en un acercamiento hacia los países de América Latina (o tuvieron al menos a la región como uno de los ejes principales de su política), la soberanía de las Islas Malvinas ha sido un eje que los decisores de política comprendieron que debía formar parte de las negociaciones con el Reino Unido; aquellos gobiernos que se enfocaron en el acercamiento directo a los países centrales del sistema internacional (Estados Unidos, Europa), la política exterior sobre las Islas Malvinas tuvo como centro la cooperación en diversos asuntos prácticos, dejando de lado -aunque sin renunciar-, la disputa de soberanía.

El movimiento pendular de la política sobre Malvinas acompañó (y aun acompaña), el movimiento pendular de la política exterior. Si la política exterior oscila entre los gobiernos que tienen entre sus ejes centrales a América Latina y aquellos que centran

3 Abordaremos el período 1989-2019, si bien el movimiento pendular de la política exterior sobre Malvinas puede rastrearse desde 1983, tras el fin del conflicto bélico y la vuelta a la democracia en Argentina.

4 Encontramos esta información en una publicación inédita de F. Nigra, que se llama Malvinas: alineamiento o integración (1973 y 2015) - una mirada desde la historia y la inteligencia artificial, disponible en Pensar Malvinas desde la Universidad. 
su política exterior en el "alineamiento" con los países centrales, el péndulo de la política sobre Malvinas oscila, de forma acompasada, según la inclusión, o no, de la cuestión de la soberanía como parte de la agenda propuesta con el Reino Unido.

\subsection{LA POLÍTICA DE ACERCAMIENTO (1989-2003)}

"La fórmula es: soberanía al final y no al principio; cooperación al principio y no al final, no supeditada a la soberanía. Y paraguas mientras tanto. Esa fue la fórmula. Y esa fue la decisión que se tomó" (Andrés Cisneros, vice-canciller de Argentina durante la década de 1990)..$^{5}$

El año 1989 marcó un cambio de rumbo de la política exterior, y de la política sobre Malvinas. En la Argentina, inició un nuevo gobierno, presidido por Carlos Menem, quien asumió tras la realización de elecciones presidenciales anticipadas. El contexto internacional estaba caracterizado por la caída del muro de Berlín y el fin de la Guerra Fría.

En palabras de Fernando Petrella, vice-canciller de Argentina entre 1992 y 1996 :

Menem tenía como prioridad restablecer las relaciones diplomáticas con el Reino Unido por lo que significaba el Reino Unido en la alianza occidental. La política hay que verla globalmente (...) cuando cae el muro de Berlín lo único que queda es la constelación occidental. No había algo para discutir, no había no alineados: o sos amigo de estos tipos o te vas a un pozo ciego. (ERLICH, 2015, p. 118).

Estos tipos eran, principalmente, Estados Unidos y el Reino Unido. La política exterior argentina durante la administración del canciller Guido Di Tella tuvo un fuerte alineamiento hacia estos países. Tal como explica Merke (2010, p. 39): “En el 90 el tema dominante fue la hegemonía norteamericana, el ascenso de un capitalismo más globalizado y la institucionalización de amplios sectores

5 Cf. Erlich (2015). 
de la política internacional". En el nuevo escenario internacional el Reino Unido era un actor prestigioso, y su estrecha relación con los Estados Unidos lo fortalecía. Restablecer las relaciones diplomáticas con el Reino Unido era para la Argentina una prioridad.

En cuanto a la Cuestión Malvinas, a partir de 1989 se llevó adelante una política de acercamiento, tal como ha sido definida por los propios decisores de política. El giro en la política exterior argentina hacia los países centrales fue acompañado por una redefinición de la perspectiva sobre Malvinas.

¿Cuáles fueron en esta etapa los objetivos de la política exterior argentina sobre Malvinas? Por un lado, la cooperación con el Reino Unido, y con los isleños, era un objetivo central. Por el otro, se mantenía formalmente el reclamo legal por la soberanía, si bien quedaba a un costado de la agenda política bilateral; a su vez, Argentina procuró obtener el apoyo de aquellos países y organismos que se pronunciaran a favor del reinicio de las negociaciones sobre la soberanía.

Las relaciones bilaterales se restablecieron finalmente a partir de los Acuerdos de Madrid (1989-1990), bajo fórmula del paraguas de soberanía. El mecanismo fue copiado de la fórmula que Argentina había llevado al Tratado Antártico: ${ }^{6}$ el paraguas de soberanía significaba que cualquier entendimiento o acuerdo que se estableciera sobre diversos asuntos prácticos, no implicaba ninguna modificación en las respectivas posiciones de soberanía de la Argentina y del Reino Unido, sobre las Islas Malvinas.

El paraguas de soberanía fue, por un lado, el mecanismo que permitió llevar adelante diversas negociaciones bilaterales dejando a un costado la cuestión de la soberanía. Por otro, de forma implícita, significaba que el Reino Unido reconocía la vigencia de la disputa, y por ello "el paraguas".

En cuanto a los isleños, la política fue llevada adelante directamente por el entonces canciller Guido Di Tella. En la reunión del Comité de Descolonización del 14 de julio de 1993 Di Tella hacía referencia al peso de las opiniones de los isleños, y su impacto en la posición británica:

6 Fue también utilizada la fórmula en los acuerdos entre Argentina y Reino Unido sobre las Islas Malvinas en 1971/72. 
[...] el establecimiento de vínculos directos con los isleños (es decir, oficiosos e informales sin el intermediario británico) ha pasado a ser un punto central de nuestra política sobre el tema (...) Sus opiniones tienen una influencia fundamental sobre la posición británica (PETRELLA, s.f., p. 6).

La política de acercamiento se centró en el establecimiento de diversos entendimientos: se firmaron en esta etapa cuarenta y siete entendimientos bilaterales entre Argentina y el Reino Unido, de los cuales alrededor de un tercio, diecisiete, fueron sobre las Islas Malvinas. Entre los más importantes se encuentra el de Conservación de Recursos Pesqueros (1990), el de Cooperación sobre Actividades Costa Afuera en el Atlántico Sudoccidental (1995) - principalmente referido a hidrocarburos - y el de Comunicaciones (1999).

Los entendimientos resultaron problemáticos desde el inicio. Principalmente, aquellos vinculados a cuestiones económicas: el de recursos pesqueros y el de hidrocarburos.

Si el espíritu de los entendimientos era para la Argentina acercar a las partes y promover, en un mediano plazo, una eventual negociación por la soberanía de las Islas Malvinas, el Reino Unido utilizó los entendimientos como un modo de legitimar el status quo y su posición en el Atlántico Sur, promoviendo numerosas acciones unilaterales tendientes a ello.

En cuanto a los recursos pesqueros, previo a la Declaración Conjunta sobre Conservación de Recursos Pesqueros de 1990, aunque también luego de la misma, se produjeron actos unilaterales británicos que:

[...] incluyeron el establecimiento de pretendidas jurisdicciones marítimas alrededor de las Islas Malvinas en 1986 y 1990, y alrededor de las Islas Georgias del Sur y Sandwich del Sur en 1993, la venta de licencias de pesca desde 1987, el levantamiento unilateral en 1994 de la prohibición total temporaria de pesca estipulada en el área descripta en el Anexo de la Declaración Conjunta del 28 de noviembre de 1990 y en el área al Oeste de aquélla (ARGENTINA, s.f., s/p.). 
En cuanto a los hidrocarburos, desde el mismo momento de la firma del entendimiento ambas cancillerías emitieron comunicados divergentes sobre el área del acuerdo y el sentido del mismo (ERLICH, 2015). Según expresaba el comunicado argentino, el entendimiento ofrecería oportunidades comerciales a empresas argentinas y a contribuir con la prosperidad económica del país, en particular, de la región patagónica; Argentina se beneficiaría de las actividades que se llevasen a cabo en áreas sujetas a la disputa de soberanía; el entendimiento y su implementación no implicaban ni podían ser interpretados como una aceptación del pretendido derecho británico a convocar a una licitación para el desarrollo de hidrocarburos en las áreas marítimas circundantes a las islas. Según el Comunicado del Reino Unido, el entendimiento alentaba una unilateral e inmediata apertura de licitaciones para que grandes empresas exploraran las costas malvinenses en busca de petróleo y gas. Si lo acordado iba a permitir la exploración conjunta de ambos países de un área definida alrededor de las islas, apenas firmado el entendimiento empezó la actividad sin la participación argentina. Asimismo, los británicos interpretaron que la cooperación se daría en un área de $21.000 \mathrm{~km}^{2}$, y se reservaba para su uso exclusivo otra de alrededor de $410.000 \mathrm{~km}^{2}$.

En cuanto a los vuelos, el entendimiento de julio de 1999, estableció un vuelo regular semanal, entre las islas y el continente, operado por la empresa chilena LAN-Airlines, entre Punta Arenas y las Islas Malvinas con dos escalas mensuales - una en cada dirección -, en Río Gallegos. Su logro conllevó una serie de dificultades debido a que:

[...] el supuesto aislamiento no les parecía - a los isleños - un verdadero problema. La tecnología, las líneas hacia Europa, la sustentabilidad económica y los cambios en el status de los pobladores, adquirida en el período posterior a la guerra, alimentaban el conocimiento de que los vínculos con Argentina no eran necesarios y hasta podían crear riesgos en el mediano plazo. (PETRELLA, 2010, p. 17).

En cuanto al reclamo por la soberanía, Argentina continuó obteniendo el apoyo de Naciones Unidas mediante una resolución 
anual del Comité de Descolonización (Comité de los 24), que llama a las partes a negociar.

A su vez, se obtuvo el apoyo a nivel bilateral y multilateral, de diversos países y organismos que se pronunciaron instando a las partes a que se restablezcan las negociaciones para alcanzar una solución definitiva: Naciones Unidas (anualmente), OEA (anualmente), Chile (1992, 1993, 1994, 2000), México, (1992, 2000), Colombia (1992, 2000), Grupo de Rio (1993) Mercosur (1996,1999), Paraguay (2000), Venezuela (2000), Bolivia (2000), Rusia (2000), Cumbres Iberoamericanas (desde el 2000), Cumbre Sudamericana (2000), Sistema de Integración Centroamericana (2000), Perú (2001), Santa Lucía (2001), Granada (2001).

En 1994, la reforma de la Constitución de la Nación Argentina incluyó una disposición transitoria sobre la cuestión de las Islas Malvinas, Georgias del Sur, Sandwich del Sur y los espacios marítimos circundantes:

DISPOSICIONES TRANSITORIAS. PRIMEIRA - La Nación Argentina ratifica su legítima e imprescriptible soberanía sobre las Islas Malvinas, Georgias del Sur y Sandwich del Sur y los espacios marítimos e insulares correspondientes, por ser parte integrante del territorio nacional. La recuperación de dichos territorios y el ejercicio pleno de la soberanía, respetando el modo de vida de sus habitantes y conforme a los principios del Derecho Internacional, constituyen un objetivo permanente e irrenunciable del pueblo argentino. (ARGENTINA, 1994, s/p.).

Quedó así, constitucionalmente instituido, que la soberanía es para la Argentina legítima e imprescriptible, y que la recuperación de dichos territorios debe darse de forma pacífica, respectando el modo de vida de sus habitantes, y conforme a los principios del Derecho Internacional.

Durante el gobierno de la Alianza (1999-2001) y el de Eduardo Duhalde (2002-2003) la política sobre la Cuestión Malvinas no presentó cambios significativos.

El gobierno de la Alianza, bajo la presidencia de Fernando de la Rúa, no modificó los lineamientos de política exterior establecidos 
por Carlos Menem (RUSSELL; TOKATLIAN, 2003). Si bien se intentó un mayor acercamiento a Brasil, la relación con los Estados Unidos "continuó siendo la directriz principal en la estrategia internacional del país" (RAPOPORT, 2009, p. 14). En cuanto a la política sobre Malvinas, hubo continuidad también con la política iniciada durante los 90. Los únicos matices se presentaron en cuanto al tono de la relación con los isleños, y en tanto Argentina dejó de participar, desde el año 2000, en la reunión del grupo de trabajo sobre hidrocarburos, en función de los desacuerdos existentes. Pero se trató principalmente de una continuidad de la política.

En palabras del entonces Canciller Adalberto Giavarini, en mayo del año 2000:

Creemos que es útil fomentar - en la medida posible y en manera articulada con el diálogo entre la Argentina y el Reino Unido- el conocimiento recíproco entre quienes habitamos el territorio continental y los isleños, para recrear una convivencia respetuosa de los intereses de todos. Esto no obsta para que, sin alterar aquellos entendimientos provisorios que sean mutuamente provechosos, debamos en cada caso objetar -en las formas previstas por el derecho internacional- la utilización unilateral británica de los recursos económicos del área marítima disputada [...] La reafirmación de nuestros derechos [...] no impide que estemos desarrollando excelentes relaciones con el Reino Unido en todos los campos (PETRELLA, s.f., p. 8).

La profunda crisis Argentina de diciembre de 2001 produjo la salida anticipada del gobierno de la Alianza presidido por Fernando de la Rúa. En la transición entre el fin de su gobierno y el inicio del gobierno de Eduardo Duhalde, en las dos semanas que transcurrieron entre el 20 de diciembre de 2001 y el 2 de enero de 2002, se sucedieron cinco presidentes. Entre ellos, Adolfo Rodríguez Saá, declaró la suspensión del pago de la deuda externa: "El default alteró drásticamente toda la ecuación diplomática construida hasta el momento por dos administraciones argentinas (Carlos Menem - Guido Di Tella y Fernando de la Rúa - Adalberto Rodríguez Giavarini)" (PETRELLA, 2010, p. 13). El Reino Unido profundizó desde entonces las acciones unilaterales. 
En un contexto de profunda crisis nacional, los objetivos de política exterior del gobierno de Duhalde se centraron en conseguir el sistema gerenciado de preferencia de Estados Unidos, un acuerdo migratorio con España y resolver el problema de la deuda externa. La política sobre Malvinas mantuvo continuidad.

\subsection{LA POLÍTICA DE FIRMEZA (2003-2015)}

“En función de estos dos elementos, no avanzamos y el reclamo está perdiendo presencia en la comunidad internacional, nos planteamos con Néstor Kirchner un cambio, que denomine después como una política de firmeza" (Entrevista a Jorge Taiana, vice-canciller 2003 - 2005 y canciller 2005 - 2010). ${ }^{7}$

En la Argentina, el año 2003 marcó un cambio de rumbo, a partir de la asunción del nuevo gobierno, presidido por Néstor Kirchner.

El contexto internacional estaba caracterizado por un escenario más multipolar, en el que actores relevantes en el escenario internacional (China, Rusia, India, Brasil) comenzaban a presionar por la modificación de las estructuras de los organismos internacionales.

En cuanto a América Latina, en palabras de Javier Figueroa, ex Director General de Malvinas del Ministerio de Relaciones Exteriores y Culto (2009 - 2013), había, "un relanzamiento de la idea de integración latinoamericana. Malvinas comenzó a formar parte de la agenda de distintos organismos" (ERLICH, 2015, p. 165).

Los cambios en el escenario mundial mostraban tres puntos centrales:

1. Un triple proceso de difusión del poder, desde Estados Unidos y Europa hacia nuevas o viejas potencias (re) emergentes, como el caso de Rusia, China, India, Brasil y Sudáfrica. Difusión de preferencias, en donde la democracia y la globalización han multiplicado la cantidad de demandas de actores públicos

7 Cf. Erlich (2015). 


\begin{abstract}
y privados buscando ser escuchadas en distintos foros formales e informales (...); 2 . Las respuestas al 11/9 y a la crisis financiera internacional han venido convergiendo en torno del regreso del Estado, la soberanía y la seguridad como valores altamente apreciados por las sociedades (...); 3 . Este orden global atestigua un regreso a problemas que durante los años 90 parecían superados (...) todas las cuestiones vinculadas con lo territorial, incluyendo recursos naturales, energía y alimentos, que han sido colocadas como prioritarias en gobiernos y organismos internacionales (MERKE, 2010, p. 39).
\end{abstract}

En ese contexto se produjeron, en América Latina, procesos políticos que confrontaron con las propuestas neoliberales. Los gobiernos que asumieron en esta época, principalmente progresistas y de izquierda, promovieron una política que buscó - con sus vicisitudes - fortalecer la integración regional. Se procuró reorientar el Mercosur al desarrollo económico y social, no sólo al libre comercio, y se crearon en este período organismos como la Unión de Naciones Suramericanas (UNASUR), en 2008, y la Comunidad de Estados Latinoamericanos y Caribeños (CELAC) - sin Estados Unidos y Canadá -, que se puso en marcha en el año 2011. Se trata de un mecanismo intergubernamental de diálogo y concertación política que, por primera vez, reunió de forma permanente a los treinta y tres países de América Latina y el Caribe.

El nuevo gobierno, presidido por Néstor Kirchner, redefinió la perspectiva y las alianzas de la política exterior, abandonando el alineamiento con Estados Unidos, propio de la década del 90. La política exterior se orientó principalmente a las alianzas en la región, aunque también hacia otros países, como China y Rusia. Las decisiones del gobierno se orientaron a la recuperación de las capacidades estatales y la redefinición de la dirección de la política exterior hacia América Latina (CARCAR; FILMUS, 2010).

Se produjo también un importante movimiento en la posición del gobierno argentino en la Cuestión Malvinas: la disputa de soberanía volvía a ser propuesta como un eje central de la agenda política con el Reino Unido. Así lo manifestó Néstor Kirchner, en su discurso de asunción presidencial y en su primer encuentro con 
el Primer Ministro Británico, Tony Blair, en Londres, en julio de 2003, cuando le expresó su intención de retomar las negociaciones sobre la soberanía de las islas

¿Cuáles fueron los ejes de la política argentina en la Cuestión Malvinas? En palabras de Jorge Taiana (vice-canciller 2003 - 2005 y canciller 2005 - 2010): “Uno de política interna, 'el fin del proceso de desmalvinización' ${ }^{8}$ Y dos de política exterior: la firmeza en la relación bilateral y la ampliación de los apoyos internacionales" (ERLICH, 2015, p. 167).

En cuanto a los ejes de política exterior, el diagnóstico del gobierno fue que los acuerdos promovidos durante la década del 90 no habían obtenido los resultados esperados. Así lo expresaba el ex canciller, Jorge Taiana:

Así como habíamos visto que en ningún momento todos esos acuerdos provisorios nos habían acercado a la mesa de negociación de la soberanía, así también habíamos visto un poco lo contrario: la realización de los acuerdos tendía a crear una cierta consolidación del statu quo y un paulatino fortalecimiento de la posición británica (ERLICH, 2015, p. 164).

Mientras que en el período 1989-2003 se promovieron entre Argentina y el Reino Unido cuarenta y siete entendimientos bilaterales, entre el 2003 y el 2015 se firmaron solamente ocho, de los cuales solo tres trataron asuntos de las islas (un único asunto). ${ }^{9}$ Esta diferencia en la firma de acuerdos es posible entenderla como la puesta en escena del movimiento en la política, que se desplazó hacia el otro lado del péndulo.

La firmeza en la relación bilateral significó la intervención del gobierno en aquellos entendimientos que comprendía que

8 Nos centraremos en los ejes de política exterior. Sobre política interna, ver Erlich (2015).

9 Así, el Canje de Notas del 3 de agosto de 2006, estableció la inclusión de la munición sin explotar que se hallaba dentro de las áreas minadas en las islas; tras ello se realizó el contrato con la Universidad de Cranfield, acordado en el Grupo de Trabajo Conjunto (GTC) Argentino-Británico, para realizar tareas del estudio de factibilidad para el desminado, y un posterior intercambio de notas aprobando el informe final del GTC. 
fortalecían la ocupación británica de las islas. En el año 2005, le envió quince notas de protesta al Reino Unido para denunciar "actos unilaterales ilegítimos", objetando las decisiones relacionadas con la explotación de la pesca y la prospección petrolera. Ante la continuidad de las acciones unilaterales y la imposibilidad de acordar una agenda, se frenaron en dicho años las reuniones de la Comisión de Pesca del Atlántico Sur (CPAS).

En cuanto a los hidrocarburos, en el año 2007 Argentina dio por finalizado el entendimiento de Cooperación sobre Actividades Costa Afuera en el Atlántico Sudoccidental (firmado en 1995) y el Congreso de la Nación aprobó, en el año 2011, la Ley Nacional n ${ }^{\circ}$ 26.659 que estableció sanciones para las empresas que operasen en el país y que estuviesen vinculadas con la exploración o explotación de hidrocarburos en las Islas Malvinas, sin la correspondiente habilitación del gobierno argentino; luego, la modificatoria Ley $n^{\circ} 26.915$ (2013) estableció sanciones penales a las empresas y dirigentes que se dedicasen a la exploración y explotación ilegales de hidrocarburos en la plataforma continental argentina (ARGENTINA, 2011; 2013).

Bolivia, en apoyo a la Argentina, se comprometió a tomar en consideración la nómina de empresas involucradas en actividades hidrocarburíferas sin autorización de Argentina, al momento de habilitar la actuación de empresas de exploración y explotación de hidrocarburos en el ámbito de su jurisdicción (CRISTINA..., 2015).

En cuanto a los vuelos, Argentina dejó de permitir los vuelos chárter que, por excepción, eran autorizados durante los 90. Propuso, en cambio, negociar un segundo vuelo a las Islas Malvinas, que partiese desde territorio continental argentino $\mathrm{y}$ mediante la aerolínea de bandera, Aerolíneas Argentinas.

Asimismo, intervino sobre las escalas de las naves y los aviones de guerra en países vecinos. Había un acuerdo del Mercosur por el cual ni los aviones ni las naves de guerra podían repostar en los puertos de los países limítrofes, pero en la práctica pedían un permiso por excepción y se concedía. El gobierno decidió exigir a 
los países limítrofes el cumplimiento de este acuerdo, como modo de no contribuir con el esfuerzo militar de ocupación británico. ${ }^{10}$

En cuanto a la búsqueda de apoyos externos, el gobierno logro importantes avances en dos niveles: por un lado, procurando el apoyo de países y organismos que llamasen a las partes a dialogar, lo cual fortalece la posición Argentina por la negativa del Reino Unido a cumplir el mandato de la comunidad internacional; por el otro, procurando el apoyo de aquellos que reconocían los legítimos derechos de la Argentina sobre las Islas Malvinas.

En cuanto a los países y organismos que convocan al diálogo, Argentina obtuvo en este período el apoyo de: Naciones Unidas (anualmente), OEA (anualmente), Cumbres Iberoamericanas (anualmente), Cumbres Sudamericanas (2004), Cumbre América del Sur-África $(2009,2013)$, Cumbres América del Sur - Países Árabes $(2005,2008,2009,2012)$, Grupo de los 77 y China (2005, 2011, 2012, 2013, 2014), Zona de Paz y Cooperación del Atlántico Sur (2007, 2013), Comunidad del Caribe (2012).

En cuanto a los países y organismos que reconocen los derechos de soberanía de la Argentina, obtuvo el apoyo de: Mercosur (anualmente), UNASUR (2009, 2010, 2011, 2012, 2013), Grupo de Rio (2004, 2005, 2007, 2008, 2009, 2010), CELAC (2011, 2014), ALADI (2004, 2005, 2008, 2014), OLADE (2013), Cumbre de América Latina y el Caribe de Integración y Desarrollo $(2008,2009)$, Cumbre de la Unidad de América Latina y el Caribe (2010), Alianza Bolivariana (2013, 2012), PARLACEN $(2012,2014)$, PARLASUR (2014).

La obtención de nuevos apoyos, de países y organismos, fortalecía el reclamo argentino. Entre ellos, el de la Cumbre América del Sur-Países Árabes (ASPA), que en 2005, 2008 y 2009 apeló a que ambos países reanudasen las negociaciones, y en 2012 solicitó al Reino Unido que se abstenga de llevar a cabo ejercicios militares en los territorios bajo controversia de soberanía. También se obtuvo el apoyo de la Cumbre América del Sur-África (ASA), que en 2009 convocó al diálogo a las partes y en 2013 reconoció los legítimos derechos de Argentina en la disputa de soberanía. Y

10 Salvo en caso de emergencia que, como estipula el Derecho Internacional, todo barco o avión puede entrar a puerto. 
el Grupo de los 77 y China, que en 2005, 2012 y 2013 llamó a las partes al diálogo.

Diversos organismos, como el Mercosur, Unasur, la CELAC, las Cumbres Iberoamericanas, la Cumbre América del Sur-Países Árabes y la Cumbre América del Sur-África, el Grupo de los 77 y China, entre otros, se pronunciaron también manifestando su preocupación y llamando al Reino Unido a abstenerse de adoptar decisiones que entrañen la introducción de modificaciones unilaterales en la situación, en cumplimiento de la Resolución 31/49 de Naciones Unidas, que convoca a las partes a no innovar en la zona en disputa. Ello ante la licitación unilateral británica de licencias de pesca, el envío de barcos militares al Atlántico Sur, la exploración unilateral de hidrocarburos, entre otras acciones.

El gobierno argentino procuró el apoyo de América Latina no solo en declaraciones bilaterales y resoluciones regionales y multilaterales, sino también a partir de medidas concretas que no favoreciesen la ocupación británica de las islas. La integración regional era para el gobierno presidido por Néstor Kirchner (2003-2007) y luego por Cristina Fernández de Kirchner (2007-2015), un elemento central en la Cuestión Malvinas.

En palabras del entonces Canciller, Jorge Taiana,

No hay recuperación de las islas en el horizonte previsible si no hay un avance en la integración regional. Porque es muy distinto que el país vecino, por amistad, por buena vecindad, porque hablamos la misma lengua o porque estamos en la misma zona, nos acompañe, que si hay efectivamente un proceso de integración y entonces se trata de una parte de lo que somos en común. Es distinto el involucramiento y es distinta la afectación (ERLICH, 2015, p. 216).

\subsection{Y LOS NOVENTA, DE NUEVO... (2015-2019)}

"Tenemos que explorar el diálogo y la colaboración con el Reino Unido más allá de Malvinas (...) Las Islas Malvinas ya no son el tema dominante en la relación entre Argentina y el Reino Unido y no debería 
desviar la atención de las prioridades bilaterales más importantes como el comercio y la inversión" (Susana Malcorra, ex Canciller de Argentina). ${ }^{11}$

La asunción de Mauricio Macri como presidente de la Argentina en diciembre 2015 marcó el inicio de una nueva etapa. El contexto internacional estaba enmarcado por políticas de cierre de fronteras y medidas proteccionistas. En el Reino Unido, era el inicio del Brexit, el referéndum realizado sobre la eventual salida del país de la Unión Europea. En América Latina, se produjo un "giro a la derecha", a partir de la asunción de diversos gobiernos conservadores en la región.

Bajo la presidencia de Macri, Argentina pretendió volver a triangular sus relaciones con Europa y Estados Unidos en un contexto en el cual este último, tras la asunción presidencial de Donald Trump, se mostraba cada vez más propenso a cerrar sus fronteras y avanzar en una política proteccionista. Ahora bien, mientras avanzaba el proteccionismo de estos países, en Argentina el nuevo gobierno insistía en abrir las importaciones e ingresar a los acuerdos de libre comercio (MACRI..., 2016).

El nuevo movimiento de la política exterior argentina, hacia el otro lado del péndulo, fue acompasado por la política sobre Malvinas: desde el inicio del gobierno, la soberanía de las Islas Malvinas dejó de ser parte de la agenda política propuesta por la Argentina. Macri fue el primer presidente electo democráticamente desde 1983 en no incluir la Cuestión Malvinas en su discurso de asunción presidencial.

Como parte de este reposicionamiento, en marzo de 2016, el nuevo gobierno quitó rango a la Secretaría de Asuntos Relativos a las Islas Malvinas del Ministerio de Relaciones Exteriores, la cual había sido creada en el año 2013 y que según la norma que le había dado origen se trataba de la "reafirmación del profundo compromiso con una causa que no solo es de los argentinos sino también de todos los pueblos que luchan por el fin del colonialismo y el

11 Cf. Tenemos... (2016). 
respeto a la integridad territorial de las Naciones independientes" (ARGENTINA, 2013b).

El Comunicado Conjunto firmado entre Argentina y el Reino Unido el 13 de septiembre de 2016 da cuenta del giro en la política exterior. En sintonía con lo señalado por Marcelo Kohen (2016), en dicho pronunciamiento se encuentran presentes las demandas británicas y no así las históricas demandas argentinas: el comunicado no remite a la Resolución 2065 (XX) de Naciones Unidas, no refiere a la Resolución 31/49 de dicho organismo, que insta a no innovar en el área en disputa, ni refiere a la presencia de la base militar británica, en una zona de paz y cooperación (ZPCAS), principal obstáculo para el desarrollo de la zona. Por el contrario, el comunicado se orienta hacia dos de las principales demandas actuales del Reino Unido: establecer vuelos a terceros países y remover las "medidas restrictivas" que adoptó Argentina en defensa de sus recursos naturales, en particular los hidrocarburíferos (ARGENTINA, 2011; 2013a).

Paradójicamente, la concesión ante las demandas británicas sobre Malvinas se producía en el contexto del Brexit y las dificultades que enfrentaba el Reino Unido. Así lo había advertido el ex ministro de relaciones exteriores del Reino Unido entre el 2010 y el 2014, William Hague, dos semanas antes del referéndum del Brexit : "el voto por la salida (leave vote) de la Unión Europea, pondría en riesgo la soberanía de las Falklands (Malvinas)" (HUGHES, 2016, s/p.).

En paralelo, Jeremy Corbyn, líder del partido laborista británico desde septiembre 2015, planteaba que el diálogo bilateral con Argentina era la única alternativa de solución a la disputa de soberanía.

Ni la eventual salida del Reino Unido de la Unión Europea ni las divisiones en la política nacional británica repercutieron en la posición del nuevo gobierno argentino.

¿Cuál fue la respuesta británica al Comunicado Conjunto del 13 de septiembre de 2016? La realización de nuevos ejercicios militares en las Islas Malvinas, que no eran nuevos. Lo novedoso era que este accionar se producía a un mes del Comunicado Conjunto, que incluía un capítulo sobre "Seguridad internacional y defensa" 
en el que se acordaba que "para enfrentar las amenazas de paz y seguridad internacional se requiere una cooperación más estrecha" (FILMUS; ERLICH, 2018, p. 12).

Tal como en los 90, la política sobre Malvinas se centró en este período en los asuntos prácticos. La negociación por la soberanía dejó de ser parte de la agenda bilateral propuesta por Argentina, si bien se mantuvo formalmente el reclamo. Los distintos comunicados emitidos por la Cancillería argentina a partir de septiembre de 2016 dan cuenta de los asuntos prácticos abordados en el periodo, que se centraron principalmente en las demandas del Reino Unido.

En cuanto a los vuelos hacia las Islas (Parte de prensa $\mathrm{N}^{\circ}$ 053/18), se avanzó en gestiones que respondían a las demandas británicas: el establecimiento de vuelos a terceros países y mediante aerolíneas de Brasil, Chile, Paraguay o Uruguay, lo cual podría favorecer la ocupación de las Islas y la eventual exploración y explotación de recursos naturales de la zona en disputa. Se dejaba así de lado las históricas demandas de la Argentina: el establecimiento de nuevos vuelos entre las islas y el territorio continental argentino, y que ello se realice mediante la aerolínea de bandera.

Asimismo, junto a un "próximo viaje de los familiares de los caídos en Malvinas a las Islas" y las gestiones para establecer nuevos vuelos, "se consideró la reanudación de las actividades de cooperación científica para la conservación de los recursos pesqueros en el área comprendida entre la latitud de $45^{\circ}$ Sur y $60^{\circ}$ Sur del Atlántico Sudoccidental y la convocatoria de la próxima reunión del Subcomité Científico de la Comisión de Pesca del Atlántico Sur" (Parte de prensa No 101/18). Las reuniones de la Comisión de Pesca (CPAS) no se realizaban desde el año 2005, a partir de las reiteradas denuncias de la Argentina de los "actos unilaterales ilegítimos" del Reino Unido sobre la prospección petrolera y la explotación de la pesca. Argentina había solicitado en 2005 discutir la relación de la cooperación con una discusión de fondo, que no estaba saldada y que era de soberanía. Las actuales gestiones se encaminaron a reactivar la comisión, dejando de lado la discusión de fondo.

¿Cuál fue el avance que es posible rescatar en este período? La continuidad de la misión humanitaria para la exhumación 
e identificación de los 123 cuerpos que se encuentran en el Cementerio de Darwin, cuyas tumbas llevaban la leyenda "Soldado argentino sólo conocido por Dios".

La iniciativa fue impulsada por centros de ex combatientes de Malvinas y emprendida a partir del año 2012, bajo la presidencia de Cristina Fernández de Kirchner, junto al Equipo Argentino de Antropología Forense (EAAF), quienes solicitaron la colaboración de la Cruz Roja. Tras las numerosas trabas impuestas por el Reino Unido, finalmente en 2017 una delegación de la Cruz Roja recogió en las islas información para la misión humanitaria que identificó los restos de combatientes argentinos. Hasta el momento, se han identificado 106 cuerpos.

El período iniciado en 2015 continúa en curso.

\section{RELECTURAS}

En las Islas Malvinas se encuentra la mayor base militar al sur del paralelo $50^{\circ}$ sur, desde donde el Reino Unido controla el despliegue militar británico en el Atlántico Sur: es uno de los territorios más militarizados del mundo, con alrededor de 1500 militares en una población total de 3000 personas, que se encuentra, además, dentro de la Zona de Paz y Cooperación del Atlántico Sur (ZPCAS). La presencia de esta potencia extra-regional y la base militar puede representar una amenaza a la paz en la región.

Es también motivo de preocupación la extracción de recursos naturales que pertenecen a la región, como el caso de los recursos pesqueros, o la exploración (y eventual explotación) de recursos hidrocarburíferos. La importancia de la biodiversidad de la zona, y la proyección antártica de las Islas Malvinas son también elementos que forman parte del presente asunto.

Desde el inicio del conflicto en 1833, y por más de 185 años, Argentina ha mantenido la continuidad jurídica del reclamo. Asimismo, a diferencia de otros casos coloniales, Argentina no ha realizado reconocimiento alguno al Reino Unido otorgándole legitimidad sobre la ocupación de las Islas Malvinas, lo cual es un importante elemento de la política exterior. 
Ahora bien, desde el restablecimiento de las relaciones bilaterales entre Argentina y Reino Unido en 1989 (aunque más precisamente, desde 1983), la Argentina presenta una política pendular en la Cuestión Malvinas entre dos principales posiciones, que son acompasadas por un movimiento pendular de la política exterior. Tales posiciones no han logrado sintetizarse, ni muchos menos resolverse, en estos treinta años, para que - junto con el reclamo formal/legal - pueda sostenerse una definida posición sobre la relación bilateral y la disputa de soberanía.

Desde ya, resulta complejo negociar con quien no está dispuesto a hacerlo, aun cuando hay más de doscientos pronunciamientos de la comunidad internacional de países que llaman a las partes a retomar el diálogo para resolver definitivamente la controversia de soberanía. Y probablemente sea doblemente complejo cuando la controversia es con uno de los integrantes del Consejo de Seguridad de Naciones Unidas, quien ocupa un lugar diferencial en el sistema internacional.

¿No es entonces esta dualidad en la política exterior argentina un elemento que puede favorecer la posición del Reino Unido?

Por otra parte, si la política de acercamiento de la década de 1990 fue utilizada por el Reino Unido para legitimar el status quo y su posición en el Atlántico Sur, ¿qué ha cambiado para que una política equivalente, o agravada, como la que Argentina promueve desde diciembre de 2015, lleve a resultados favorables en un contexto, incluso, signado para el Reino Unido por las dificultades del Brexit?

\section{REFERENCIAS}

ARGENTINA. Constitución (1994). Constitución de la Nación Argentina, publicada en el boletín oficial del 23 de agosto de 1994. Santa Fé: [s.n.], 1994. Disponible en: <https://www.acnur.org/fileadmin/Documentos/ BDL/2001/0039.pdf>. Acceso en: 24 feb. 2019.

Ministerio de Justicia y Derechos Humanos. Ley nacional n²6.659, promulgada de hecho en 12 de abril de 2011. Establécense condiciones para la exploración y explotación de hidrocarburos en la Plataforma Continental Argentina. Buenos Aires: [s.n.], 2011. Disponible en: <http:// 
servicios.infoleg.gob.ar/infolegInternet/anexos/180000-184999/181076/ norma.htm>. Acceso en: 24 feb. 2019.

Ley nacional $\mathrm{n}^{\circ}$ 26.915, promulgada en 05 de diciembre de 2013. Modifica la ley nacional $\mathrm{n}^{\circ}$ 26.659, de 12 de abril de 2011. Buenos Aires: [s.n.], 2013. Disponible en: <http://www.casi.com.ar/sites/default/files/ Ley\%2026915\%20\%2009\%2012\%202013.pdf>. Acceso en: 24 feb. 2019.

Decreto $^{\circ} 2.250$, de 19 de diciembre de 2013. Modifica y complementa el decreto $n^{\circ}$ 357, de 21 de febrero de 2002. Buenos Aires: [s.n.], 2013. Disponible en: <http://servicios.infoleg.gob.ar/infolegInternet/ anexos/220000-224999/224155/norma.htm>. Acceso en: 05 mar. 2019.

Ministerio de las Relaciones Exteriores y Culto. Cuestión Malvinas. Buenos Aires: [s.n.], [s.f.]. Disponible en: <http://evene.mrecic.gov.ar/es/ content/cuestion-malvinas-0>. Acceso en: 24 feb. 2019.

BOBBIO, N.; MATTEUCI, N.; PASQUINO, G. Diccionario de política. México: Siglo XXI, 1991.

CARCAR, F.; FILMUS, D. Educación y trabajo en América Latina y Argentina en las últimas dos décadas. In: FILMUS, D. (comp.). Crisis, transformación y crecimiento: América Latina y Argentina (2000 - 2007). Buenos Aires: EUDEBA, 2010. p. 79 - 144.

CRISTINA y Evo ratificaron la relación estratégica de Argentina y Bolivia y el derecho de nuestro país sobre Malvinas. Télam - Agencia Nacional de Noticias, Bueno Aires, 16 jul. 2015. Política. Disponible en: <http://www. telam.com.ar/notas/201507/113055-cristina-fernandez-de-kirchner-evomorales-argentina-bolivia-malvinas.html>. Acceso en: 24 feb. 2019.

ERLICH, U. Malvinas: soberanía y vida cotidiana. Córdoba, Ar: Eduvim, 2015.

FILMUS D.; ERLICH, U. Claudicación macrista. Revista Maíz, La Plata, Ed. especial Malvinas, p. 10 - 13, 2018. Disponible en: <http://sedici.unlp. edu.ar/bitstream/handle/10915/66539/Documento_completo.pdf-PDFA. pdf? sequence $=1$ \&isAllowed=y $>$. Acceso en: 05 mar. 2019.

GROUSSAC, P. Las islas Malvinas. Buenos Aires: Lugar Editorial, 1982.

HOBSBAWN, E. Historia del siglo XX. Buenos Aires: Crítica; Grijalbo Mondadori, 2001.

HUGHES, L. Brexit would put Falkland Islands' sovereignty at risk, says William Hague. The Telegraph, [online], 8 jun 2016. News. Disponible en: <https://www.telegraph.co.uk/news/2016/06/08/brexit-would-putfalkland-islands-sovereignty-at-risk-says-willi/>. Acceso en: 05 mar. 2019. 
KOHEN, M. Las Malvinas tuvieron su martes 13. Clarín, Buenos Aires, 16 sep. 2016. Opinión. Disponible en: <https://www.clarin.com/opinion/ malvinas-martes-13_0_rJH6A19h.html>. Acceso en: 24 feb. 2019.

MACRI está confundido en la política exterior. Página 12, Buenos Aires, 27 nov. 2016. Disponible en: <https://www.pagina12.com.ar/5465-macriesta-confundido-en-la-politica-exterior>. Acceso en 5 mar 2019

MERKE, F. Las responsabilidades de la política exterior argentina. Voces en Fénix, Córdoba, a. 1, n. 4, p. 39 - 41, 2010. Disponible en: <http:// www.vocesenelfenix.com/sites/default/files/numero_pdf/vocesN4final. pdf>. Acceso en: 24 feb. 2019.

NU - Naciones Unidas. Resolución 2065 (XX) de la Asamblea General de las Naciones Unidas. Cuestión de las Islas Malvinas (Falkland), tratada en sesión pública de 16 de diciembre de 1965. Dipublico.org - Derecho Internacional, [online], 04 jul. 2010. Disponible en: <https://www. dipublico.org/5886/resolucion-2065-xx-de-la-asamblea-general-delas-naciones-unidas-cuestion-de-las-islas-malvinas-falkland-islands/> . Acceso en: 24 feb. 2019.

PETRELlA, F. La disputa de las islas Malvinas y su contexto histórico. Anales de la Academia Nacional de Ciencias Morales y Políticas, Buenos Aires, s.v., p. 01 - 16, 2010. Disponible en: <https://www.ancmyp. org.ar/user/files/01-Malvinas.pdf>. Acceso en: 24 feb. 2019.

Estudio preliminar sobre Malvinas. CARI - Consejo Argentino para las Relaciones Internacionales, Buenos Aires, tomo VIII, [s.f.].

RAPOPORT, M. Argentina: economía y política internacional - los procesos históricos. Diplomacia, Estrategia \& Política, Brasília, n. 10, p. 27 - 51, 2009.

RUSSELL, R.; TOKATLIAN, J. G. El lugar de Brasil en la política exterior argentina. Buenos Aires: Fondo de Cultura Económica, 2003.

TENEMOS que explorar el diálogo y la colaboración con el Reino Unido. Télam - Agencia Nacional de Noticias, Buenos Aires, 18 may. 2016. Política. Disponible en: <http://www.telam.com.ar/notas/201605/147854malcorra-malvinas.html>. Acceso en: 24 feb. 2019. 